\title{
EXPLOSIVE BLAST INJURY
}

\section{LIEUTENANT-COLONEL M S OWEN-SMITH, MS, FRCS, RAMC \\ Professor of Military Surgery \\ Royal Army Medical College, Millbank}

Explosives are substances which, when detonated, are very rapidly converted into large volumes of gases. When the explosion is confined by some form of bomb or shell casing, the pressure ruptures the casing imparting high velocity to the resulting fragments. The remainder of the energy then produces the blast shock wave, fire and ground shock. There are three components of the compound blast wave in air: positive phase, negative phase and the mass movement of air.

Positive phase.

The blast wave starts with a single pulse of increased pressure lasting a few inilliseconds (msec), this layer of compressed air has an extremely sharp front less than one thousandth of an inch thick in which the pressure arises almost instantaneously to peak levels. It then decays exponentially with time to reach a minimum pressure which is less than the previous ambient pressure (Figs 1 and 2). The time

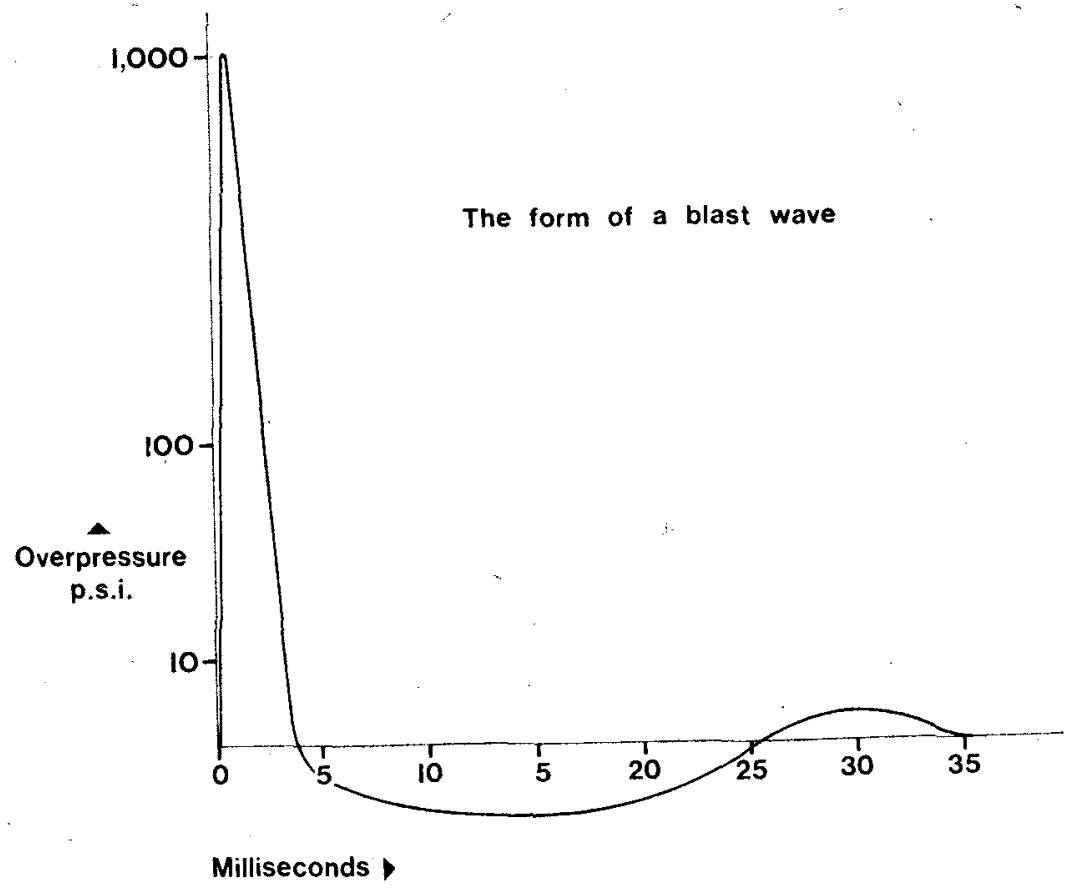

Fig. 1. The form of a biust wave

- Based on a presentation to the CENTO Medical Conference at the Royal Army Medical College in June 1978. 


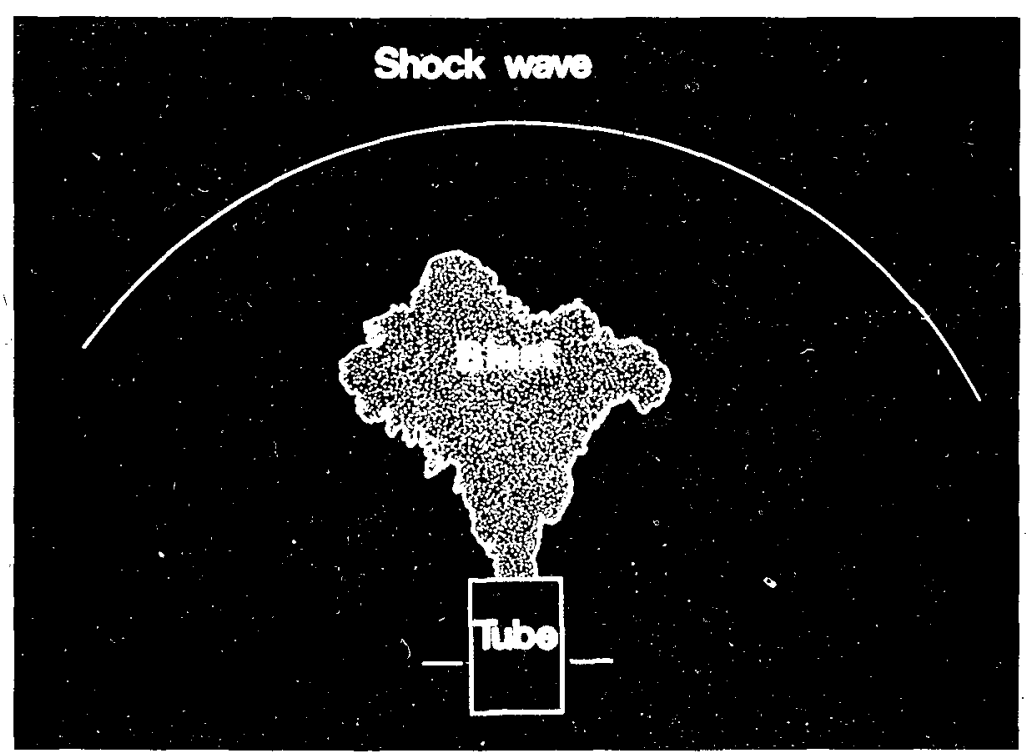

Fig. 2. Drawing of a high speed photograph of an explosion of a mixture of pentane and air. This shows the expanding gases and the shock wave

constant is a function of the type of explosive and the distance from the point of detonation. For trinitrotoluene (TNT) an overpressure of 100 pounds per square inch (psi) may be associated with a duration of $2 \mathrm{msec}$ for a $50 \mathrm{lb}$ charge and 10 msec for a 4,000 $\mathrm{lb}$ charge. For yields of 1 Kiloton the duration of the pulse is about $100 \mathrm{msec}$ and for 1 Megaton about 1 second (Cardole 1967, Rawlins 1978). The duration of the pulse is important, for it represents the time an object in the path of the shock wave is subjected to the pressure squeeze. The blast wave moves away from the source in the form of a sphere of compressed gas, which is expanding rapidly. The velocity of the blast shock wave in air may be as high as 10,000 feet per second but it soon falls to the speed of sound within a variable distance depending upon the amount and composition of the explosive.

The maximum pressure of the blast wave immediately adjacent to the explosive charge is extremely high. Thereafter the pressure falls off as the wave moves away from the source of the explosion (Fig. 3). For example with TNT a $70 \mathrm{lb}$ charge produces 100 psi at 15 feet and 6 psi at 50 feet, whereas a $125 \mathrm{lb}$ charge produces $200 \mathrm{psi}$ at 15 feet and $10 \mathrm{psi}$ at 50 feet. These figures represent hydrostatic pressure in excess of normal atmospheric pressure.

The Incident pressure is the pressure level at $90^{\circ}$ to the direction of the travel of the blast shock front. Like sound waves the blast pressure waves will flow over and around an obstruction, like a wall, and affect someone sheltering behind it (Fig. 4). The Reflected pressure is a rapid build up of pressure that occurs when a shock front strikes a flat surface in its line of travel, a person standing near a wall facing an explosion would be exposed to Reflected pressure (Fig. 5). This pressure may be several times greater than the Dynamic pressure (United States National Bomb Data Center 1974). 


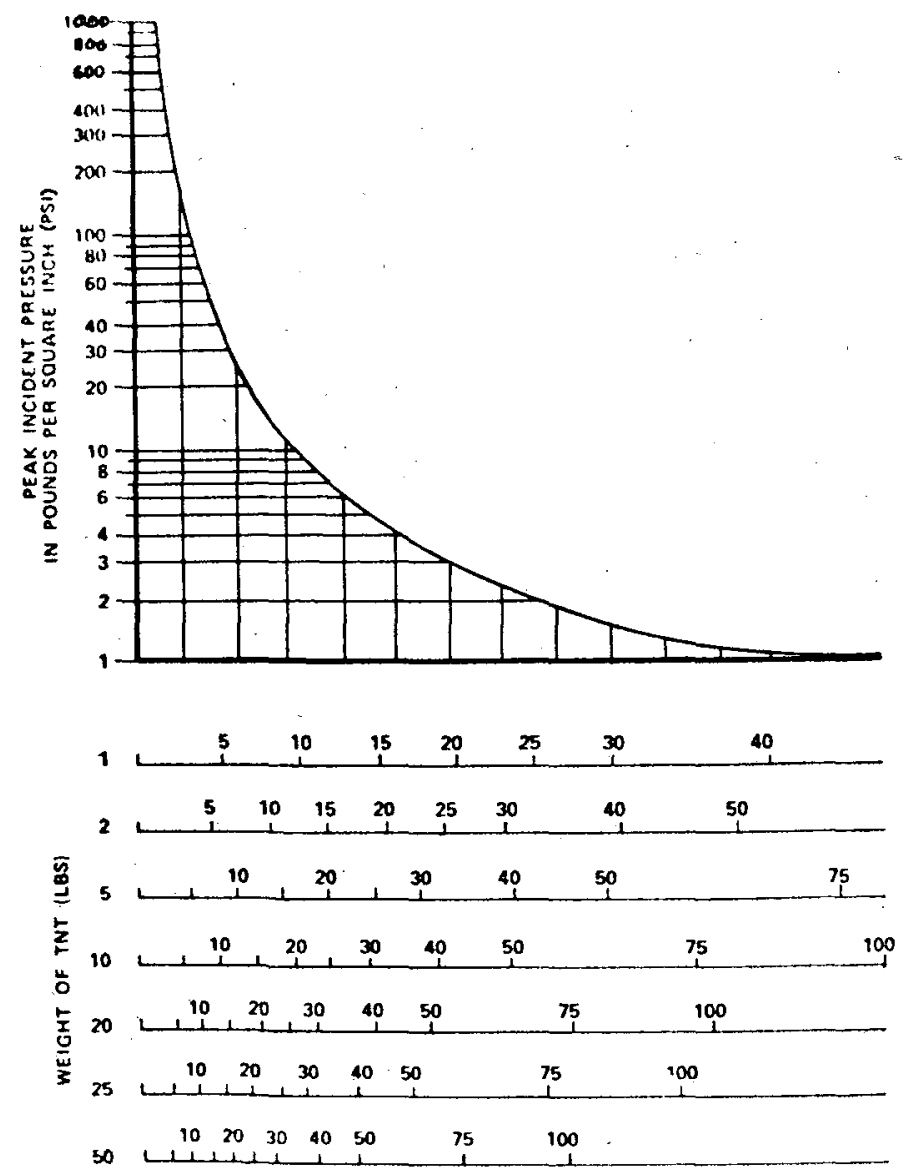

DISTANCE FROM POINT OF OETONAIION (FI)

Fig. 3. Peak incident pressure plotted against distance from detonation of TNT. From this graph the approximate incident pressure can be calculated for known weight of explosive at known distances. (After NBDC 74-9)

Negative phase

The negative pressure or suction component of the blast wave is much less than the positive pressure phase and can never be greater than $15 \mathrm{psi}$. It follows immediately after the positive wave but lasts about ten times as long.

Mass movement of air

The rapidly expanding gases from an explosion displace an equal volume of air and this air rushes out at a very high velocity (Figs 6 and 2). Any surface facing an explosion will be subjected not only to the excess hydrostatic pressure but also a pressure from this high velocity wind of the mass movement of air which travels immediately behind the shock front of the blast wave. This is called Dynamic pressure (Fig. 4). Close to the explosion this Dynamic pressure may be as great as the hydrostatic pressure of the shock front, but further from the explosion the effect falls off rapidly. The very high wind associated with blast overpressures are em- 
phasised by the fact that a hurricane force wind of 125 miles per hour only exerts an overpressure of 0.25 psi.

This mass movement of air is capable of causing injuries of all degrees of severity, in the immediate vicinity of the explosion it may cause total disintegration of the body, lesser levels will cause disruption of tissues, traumatic amputations and evisceration. The form of the blast wave is usually very distorted due to the unevenness of the terrain, the additive and substractive effects of wave interference and bounce and the sheltering effects of interposed objects that absorb some of the energy of the wave.

\section{Explosions under water}

The blast wave travels much more rapidly (4,800 feet per second) and much

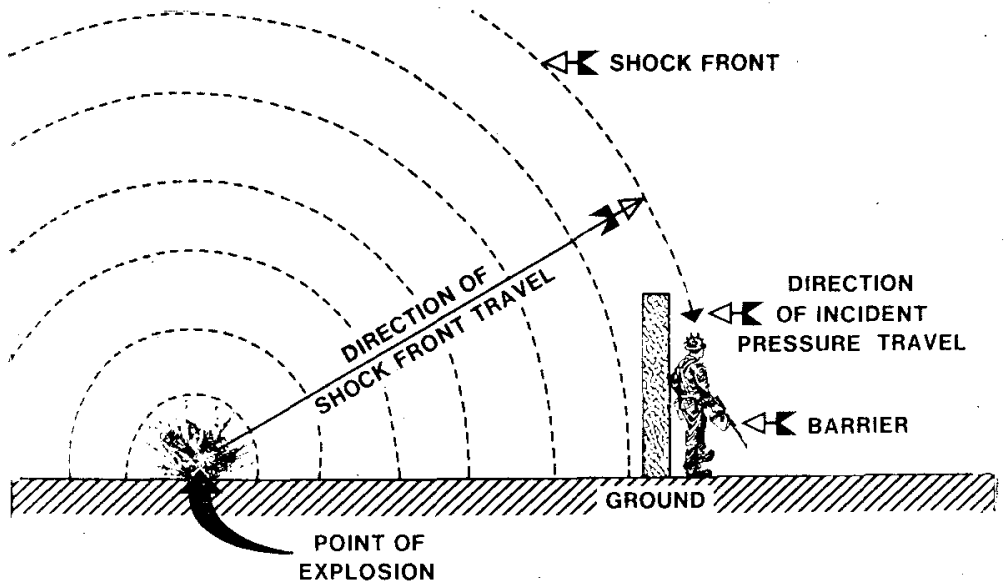

Fig. 4. Diagram of explosion showing the direction of propogation of the blast wave and how the incidental pressure will affect a subject sheltering behind a wall

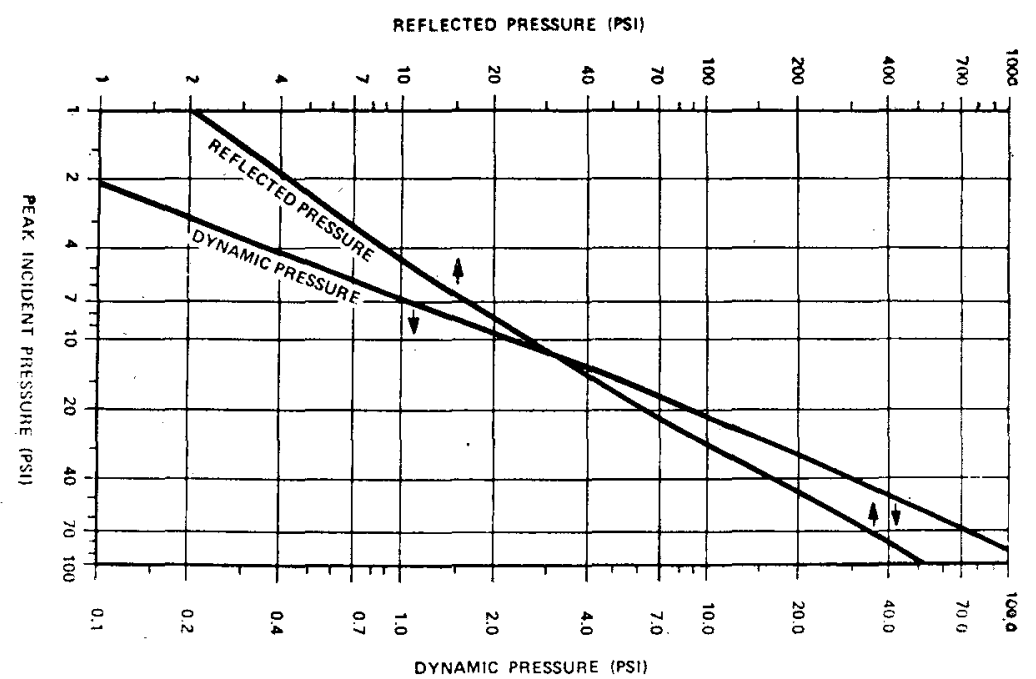

Fig. 5. Reflected pressure and Dynamic pressure related to Peak Incidence Pressure. (After NBDC 74-9) 


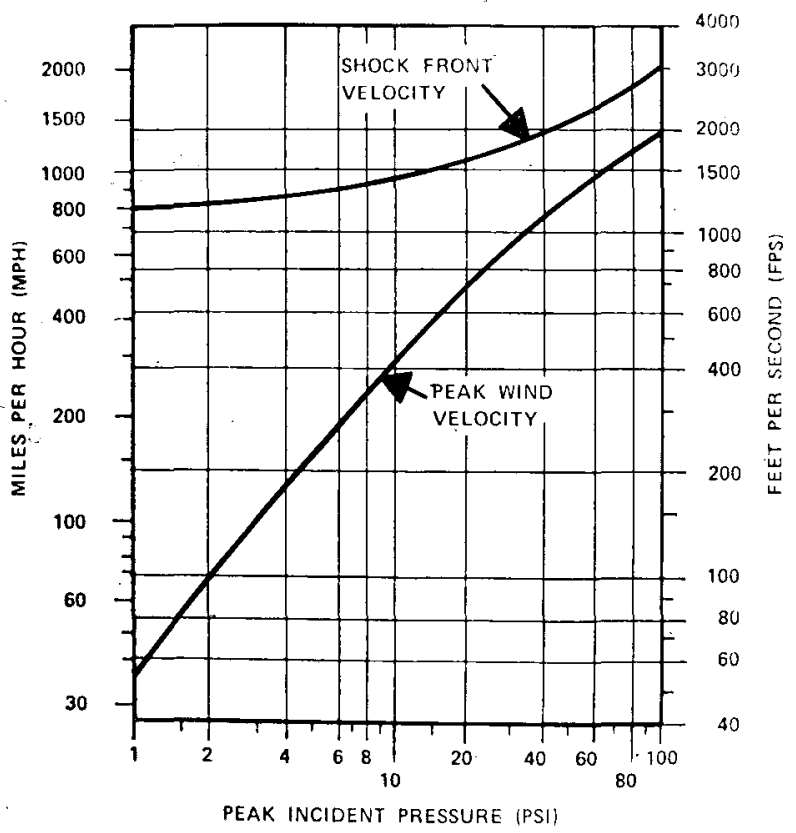

Fig. 6. Peak wind velocity and shock front velocity related to peak incident pressure. (After NBDC 74-9)

further in water due to the greater density of the medium and its relative incompressibility and that is why blast injuries in water are more severe at a greater distance than they are in the air. There is no negative phase and there is very little mass movement of water even close up to the explosion. Corresponding values for pressures are much higher in water shock waves than in air, for example a $250 \mathrm{~g}$ charge produces a peak pressure of 3,000 psi at $2 \mathrm{~m}$ and a $100 \mathrm{~kg}$ charges 25 psi at a range of $700 \mathrm{~m}$.

Special physical phenomena cause injuries in ways other than the direct effect of blast. When the pressure front travels from one medium to another of less density, such as the fluid air interfaces of the alveoli, there occurs at the interface a reflection which creates local tension in the first medium. This phenomenon is known as "spalling" and causes fragmentation, oedema and haemorrhage in the lung, or in the wall of the air containing hollow viscus involved. It may be demonstrated by the physical changes that are observed at the water surface where an underwater explosion occurs, a dome of spray is produced from the superficial layer of the water because of the change from static energy of the blast wave to kinetic energy.

If the blast wave travels in a fluid medium of living tissues and comes into contact with small air bubbles which are compressible it results in a reduction in the volume of the bubble and the development of very high local pressures. This phenomenon is known as "implosion" and causes further damage to the tissues at risk.

Clinical experience and animal experiments have shown that the most vulnerable organs are the ear-drums, lungs and the gastro-intestinal tract.

Finch (in Williams 1941) was able to demonstrate a photograph of the blast 
wave which was of an explosion of a mixture of pentane and air with an exposure time of one millionth of a second. It was observed that the gases ejected from the end of the tube present an irregular molecular spray, the velocity of which is approximately 5,000 feet per second. This sets up a pressure wave by the compression effect of the spray acting upon the inherent inertia of air and the photograph demonstrates the pressure wave as a part of a sphere of rapidly increasing radius (Fig. 2). Such a shock wave can also be demonstrated in a fluid medium and both of these are remarkably similar to the shock wave that occurs in a fluid medium when it is penetrated by a high velocity projectile. The effects of the blast pressure wave on structures exposed on open ground to an unconfined explosion and to unprotected persons are shown in the accompanying Tables I and II.

Table I

Blast pressure effects upon structures on open ground

\begin{tabular}{|c|c|}
\hline Pressure (psi) & Structure or material \\
\hline 0.1 to 5 & Shatter single strength glass \\
\hline 1 to 2 & $\begin{array}{l}\text { Crack plaster walls: Shatter asbestos sheet: Buckle steel } \\
\text { sheet: Failure of wood wall }\end{array}$ \\
\hline 2 to 3 & Crack cinder block wall: Crack concrete block wall \\
\hline 2 to 8 & Crack brick wall \\
\hline 5 to 10 & Shatter car safety glass \\
\hline
\end{tabular}

(D.A.S.A. 1860 (1966) from United States National Bomb Data Center (1974))

Table II

Short duration pressure effects upon unprotected persons

\begin{tabular}{|l|l|}
\hline Pressure (psi) & \multicolumn{1}{c|}{ Effect } \\
\hline 5 & Slight chance of ear-drum rupture \\
\hline 15 & Fifty per cent chance of ear-drum rupture \\
\hline 30 to 40 & Slight chance of lung damage \\
\hline 80 & Fifty per cent severe lung damage \\
\hline 100 to 200 & Slight chance of death \\
\hline 130 to 180 & Fifty per cent chance of death \\
\hline 200 to 250 & Death usually \\
\hline
\end{tabular}

(D.A.S.A. 1860 (1966) from United States National Bomb Data Center (1974))

\section{Historical}

During World War I a number of fatal casualties occurred in soldiers who had been close to the explosion of shells and mines and whose bodies showed no signs whatever of external injury. Mathew in 1917 drew attention to the effect produced by submarine mine explosion upon men in the water and he gave a description of 10 men with abdominal and pulmonary symptoms and signs from the effect of such an explosion. Experiments at that time showed that rabbits were killed if ex. 
posed at a short distance from an explosion, and that the area within which this fatal effect was caused was almost ten times as great in water as in air. The main pathology was found to be massive haemorrhage in the lung with pulmonary and central nervous systems signs. Hooker in 1924 studied the effects of blast from TNT and gunfire on animals. He found that bruising and rupture of the lungs was the single gross lesion found at post mortem examination. Some animals died immediately, others after an interval and some survived; small animals like rabbits and cats died when exposed to the same blast which larger animals like dogs survived without obvious harm.

In 1939 there was speculation about how pulmonary lesions were caused in air blast injuries and three possibilities were suggested:

1. The lesions were due to a lowering of alveolar pressure by the suction wave acting through the respiratory passages with consequent rupture of the alveolar capillaries.

2. The lesions were caused by distension of the lungs with air.

3. The lesions were due to the impact of the pressure wave on the chest wall.

In 1940 Zuckerman set out to elucidate the matter. He carried out experiments on small animals in two ways. First, they were exposed at various distances to blast from charges of TNT placed in paper containers on the ground and in the second, the animals were exposed to blast from the explosion of charges of hydrogen and oxygen in balloons. He confirmed that there was much species vaniation in susceptibility, but in general the larger the animal the less severe was the damage and he noted that no lesions were observed at pressure of 5 psi. Small animals such as rabbits might be killed instantaneously at pressures of $50 \mathrm{psi}$ and all were killed as pressures approached $100 \mathrm{psi}$. He found that there was a range of pressure in which all animals of the same species were killed without any external signs of injury. Further from the explosion, there was a zone of pressure in which the animals were found alive but who usually died within 24 hours. His summary was that the blast of high explosive caused haemorrhagic lesions in various internal organs of the experimental animals without causing any external injury. The most conspicuous lesions were found in the lungs, where they varied from small superficial haemorrhages to haemorrhage which affected the entire substance of the lung. These lesions were also observed in other viscera and in the sub-mucosa of the trachea. Rupture of the ear-drums was noted almost uniformly. The experiments had shown that thoracic and abdominal lesions were due to the impact on the body wall of the pressure wave and not to any effect of the suction wave. The pulmonary lesions were thus comparable with haemorrhage lesions which may occur as a result of severe falls or direct blows on the chest wall. Much of his work was confirmed by Krohn et al (1942) and Clemedson in 1949.

After establishing the pressures that killed animals, attempts were made to find out the pressures necessary to injure those parts of the body most sensitive to blast. The ear-drums proved to be the most vulnerable. Pressures required to rupture 50 per cent of exposed drums was under $15 \mathrm{psi}$. The minimal pressure likely to damage the lungs was calculated to be about 50 psi. Benzinger (1950) protected some animals with a plaster jacket to cover the thorax and abdomen; these animals 
did not develop lung changes even when the tracheo-bronchial tree was exposed to the blast by means of a tracheostomy. Desaga (1943) showed that a unilateral pneumothorax protected the underlying collapsed lung and that damage from the blast only occurred to the lung on the opposite side.

Damage to the abdominal viscera is proportionally rare in air blast and the experiments had shown that most animals who did have abdominal injuries had been killed by the explosion. Such injuries were mainly localised to the gastro-intestinal canal especially to those parts containing gas where both haemorrhage and perforation could occur.

Blast effects in water

First described in 1917, these were more fully described by Zuckerman in 1940 and 1941 with a clinical presentation of abdominal pain and commonly haemoptysis, haematemesis and diarrhoea. Many had rupture of the bowel, or multiple petechial haemorrhages in the intestine, and injuries to the lung.

The pathological changes resulting from experimental under-water explosions were reported in detail by Cameron, Short and Wakeley $(1941,1942)$. The striking feature was the absence of external injury, the most severe changes were seen in the respiratory system and consisted of pulmonary haemorrhage, bronchial and tracheal haemorrhage, acute vesicular and interstitial emphysema and occasional pneumothorax and haemothorax. Damage to the abdominal contents was only seen closer to the explosion and the lesions included rupture of the stomach or large bowel, subserous haemorrhages and haemorrhage in the mucous coat of the small intestine. It was noted that hollow viscera that were filled with fluid such as the gall bladder, the urinary bladder and the renal pelves escaped injury. This was in striking contrast with the behaviour of air containing viscera which often showed damage.

\section{Injuries to the lung}

Haemorrhages in the lung are mainly confined to the side turned towards the explosion. They are mainly localised to the apices and to those parts of the lung which become compressed and contused between the chest wall and the liver and the chest wall and the mediastinum. The mechanism is probably that the lungs become compressed between the rigid spine, the inward moving thoracic wall and the rising diaphragm. The diaphragm rises violently under the ram effect of the abdominal viscera when the pressure wave compresses the abdominal wall. To this must be added the damaging effects of "spalling" and "implosion".

Gastro-intestinal system

Damage to the gut is unusual in air blast but more common in underwater explosion. Gross damage and evisceration do occur in fatal cases who are very close to the centre of an explosion. When the closed injuries result they usually take the form of perforation of the air containing viscera, normally the large bowel and stomach, or multiple haemorrhages into the wall and lumen of such structures. The clinical presentation is of abdominal pain and melaena, and examination reveals signs of peritonism and commonly gas under the diaphragm.

Auditory system

Explosive blast can damage the hearing in three ways: 
1. Rupture of the Tympanic Membrane which occurs in human adults at pressures of about 7 psi and is usually complete in children by 30 psi.

2. Dislocation of Ossicles which can take place whether or not the drum is perforated.

3. Damage to the Inner Ear. Severe deafness often occurs on exposure to blast pressures. Depending on the level of pressure, much of the deafness may recover over a period of hours or days. Those with irreversible inner ear damage will be permanently deaf.

Nervous system

The neurological changes are among the most striking phenomena which follow blast. The general and focal cerebral systems are altogether lacking when only the head is exposed to the blast, on the other hand they are present when the head is not exposed. Therefore the cause of all cerebral symptoms must be sought in damage to the trunk. Benzinger's (1950) work strongly supports that the central nervous system changes are due to cerebral air embolism which originate from pulmonary damage.

Coronary artery air embolism

Benzinger (1950) proved that arterial air embolism in the coronary arteries was one of the major causes for sudden death from blast and that cerebral air embolism was the main cause for the central nervous system symptoms. After exposure to blast, air embolism in the systemic circulation is only found in the arteries and not in the veins. This makes the condition distinctly different from the syndromes of Caisson disease or decompression sickness. He showed that air enters the circulation when damage occurs to the pulmonary tissues with breaks in the interface between the air spaces and also in the pulmonary veins. He noted that cerebral air embolism was found at autopsy only among those animals which died immediately, cerebral focal symptoms were found among those who survived longer. Benzinger showed that all animals who were killed immediately by the explosion had air embolism of the coronary vessels whereas this was not found in the surviving animals. Arterial air embolism was induced by injecting air into the pulmonary veins of experimental animals, this caused death from coronary air embolism and as little as $1 \mathrm{ml}$ of air was sufficient to cause death. He also proved that cerebral air embolism occurred in experimental animals and that the air was absorbed after about ten minutes. He demonstrated with experimental air embolism both of the coronary arteries and cerebral arteries, that the fatal effects could be completely reversed by subjecting them to positive pressure and slow decompression. He was able to save animals exposed to a previously fatal level of pressure from an explosion by placing them immediately in an atmosphere of increased pressure at three atmospheres followed by slow decompression. The animals survived a level of pressure which had previously been associated with death from coronary artery air embolism. He concluded that air embolism of the coronary arteries is by no means the only cause of death, but the theory of air embolism solves the mystery of the rapidity, uniformity and precision of death by blast.

In Northern Ireland the total number of people killed by bomb explosions and 


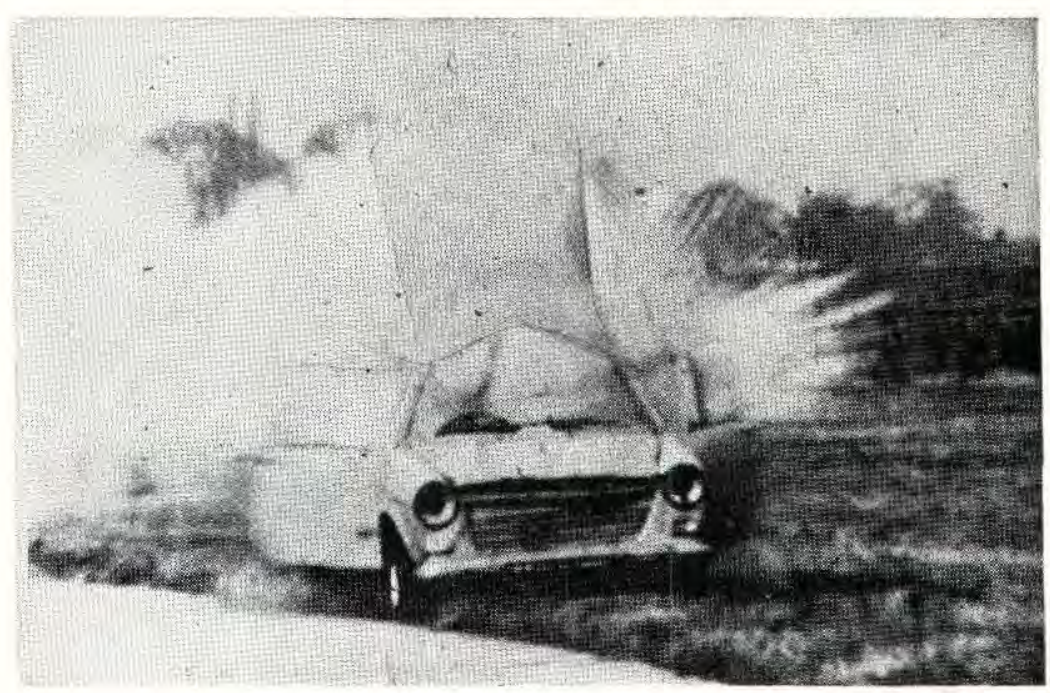

Fig. 7. Controlled explosion (6oz) of a car

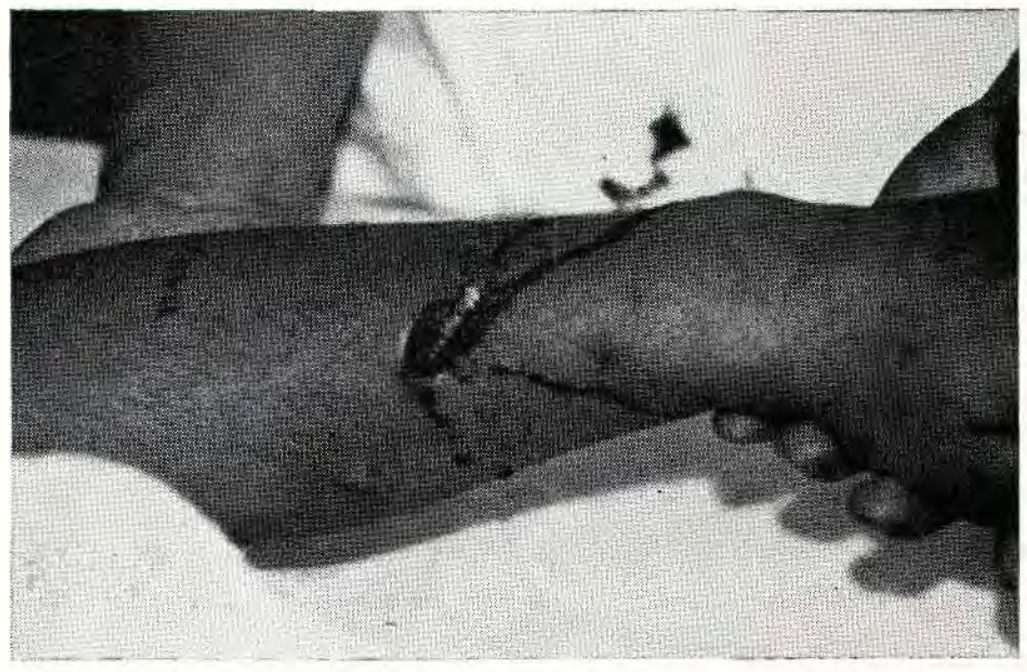

Fig. 8. Screw from home made bomb impacted in the radius

bullets from 1969 to the end of 1977 was 1,820 and nearly 20,000 have been injured, During this period the total number of recorded bomb explosions was over 5,000 with over 500 killed and over 5,000 wounded (Figs. 7 to 10). Seventy of these explosions had been in England with 62 deaths out of 868 injured (Hill 1978). Up to August 1976 over 2,700 were admitted to hospital as a direct result of bullet wounds and blast injury and approximately 10 per cent of these have been admitted to the intensive care unit (ICU) at the Royal Victoria Hospital, Belfast (Coppell 1976). Over 650 patients were admitted following bomb explosions and of these approximately 80 were transferred to the ICU. Nineteen of these developed respiratory failure, but in only eight could the diagnosis of blast injuries of the lung 
be confidently made. Blast injuries of the lungs are, therefore, surprisingly uncommon when it remembered that the force of the explosion is sufficient to cause traumatic amputations or disintegration of the body at close range. Lung damage can arise from the primary blast effect and also from the patient being thrown against a solid object in the environment by the force of the explosion.

Patients with primary blast injuries of the lungs usually present with signs of anoxia. They may have dyspnoea of sudden onset, haemoptysis, cyanosis, moist

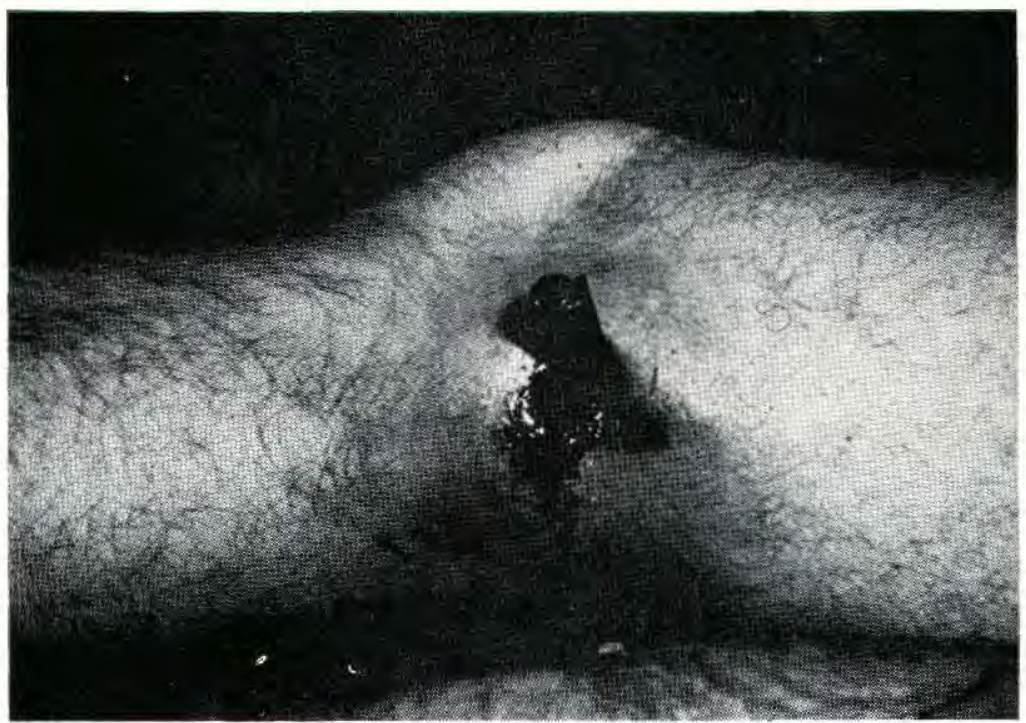

Fig. 9. Six inch bolt from a home made bomb driven through the knee joint, fortunately missing the popilteal vessels

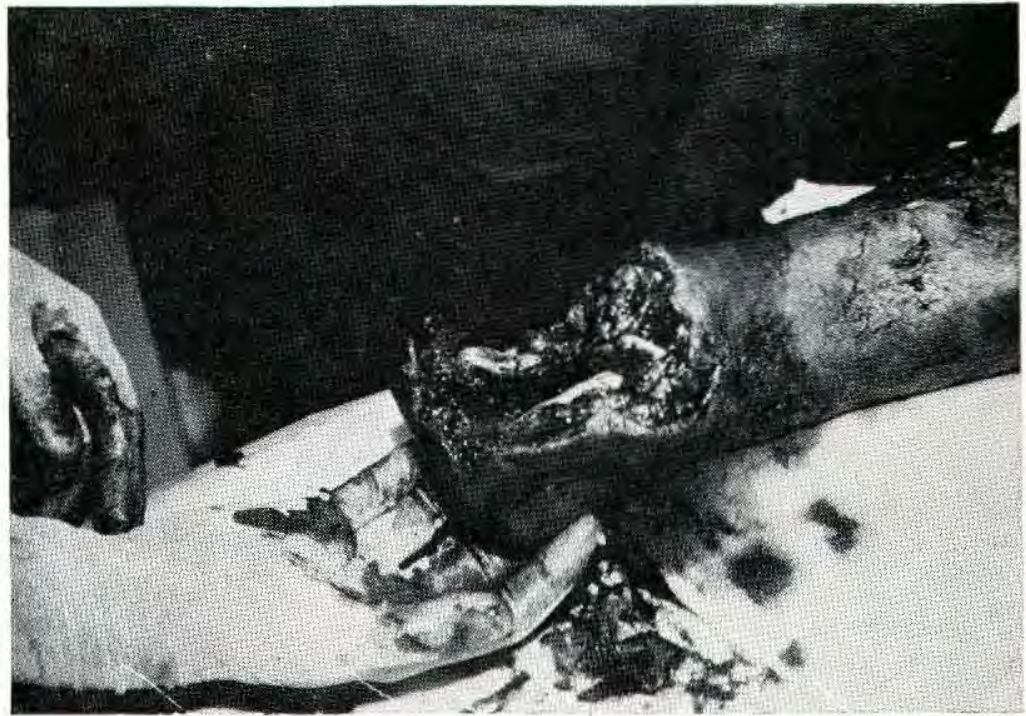

Fig. 10. Traumatic amputation from an anti-personnel mine in Oman 
crepitations in both lung fields and chest X-ray may reveal pneumothoraces or bilateral intrapulmonary haemorrhage and oedema. External injuries may be extensive or relatively superficial. Respiratory failure commonly develops after 12 to 36 hours delay and this could be due to a combination of the blast effects, fat embolism syndrome if there are multiple fractures, iatrogenic fluid overload or aspiration pneumonia. The terminology that has been used to describe this pathological state has caused considerable confusion. There is a multiplicity of phrases such as "shock lung", "blast lung", "wet lung", "stiff lung", "high output pulmonary insufficiency" and all these phrases just describe one aspect of the clinical state or relate to the aetiology. Probably the best name to be applied to the end result of many different types of insult is "post traumatic pulmonary insufficiency" (Moore et al 1969) for this acknowledges the fact that there is no single entity that is responsible for these changes but there are a number of factors each having their own effect and related to each other. The lung can only respond in a limited way to a number of different types of trauma. The total effect of these insults is to produce a severe and life threatening impairment of lung function. Treatment consists of intermittent positive pressure ventilation, often with a positive end expiratory pressure, high concentrations of inspired oxygen, steroids and diuretics.

In those who die, the lungs at post mortem are like liver in appearance and are heavy, haemorrhagic and oedematous. The rib markings can often be seen, with multiple punctate haemorrhages occurring along the intercostal spaces. Lacerations, if present, are often found along these lines.

The mortality in the intensive care unit of the Royal Victoria Hospital in Belfast for bomb blast injuries was 30 out of 79 ; that is nearly 40 per cent, but it is stressed that only a few of these were pure blast injuries, uncomplicated by severe, multiple penetrating injuries. A greater awareness of the mechanical stresses involved in blast pressure effects and the physiological changes they create could help clinicians who are presented with the management of patients damaged by explosive blast effects.

\section{Acknowledgement}

My thanks are due to my Surgical colleagues for their contributions to the Department's slide library, some of which are reproduced here.

\section{REFERENCES}

Benzinger, T (1950). German Aviation Medicine in World War II. Vol. 2, Chapter 14. United States Department of the Air Force.

Cameron, G R. Short, R H D and Wakeley, C P G (1941). Pathological changes produced in animals by depth charges. British Journal of Surgery. 30, 49

Cameron, G R. Short, R H D and Wakeley, C P G (1942). Abdominal injuries due to underwater explosions. British Journal of Surgery. 31, 51 .

CARDole, C A de (1967). Blast injury. Canadian Medical Association Journal. 96, 207

Clemedson, C J' (1949). An experimental study of air blast injuries. Acta physiologica Scandinavica. 18, suppl 61

CoppelL, D L (1976). Blast injuries of the lung. British Journal of Surgery 63, 735

DESAGA, $\mathrm{H}$ (1943). Quoted by Benzinger (1950)

HOOKER, D K (1924). Physiological effects of air concussion. American Journal of Physiology 67, 219

HiLl, J (1978). Personal communication

Krohn P L. WhitTeridge D and Zuckerman, S (1942). Physiological effects of blast. Lancet i, 252 
MATHEW, W E (1917). Notes of the effects produced by a submarine mine explosion. Journal of the Royal Naval Medical Service. 3, 108

Moore, F D et al (1969) Post Traumatic Pulmonary Insufficiency. W. B. Saunders \& Co. Philadelphia.

Rawlins, J S P (1978). Physical and pathophysiological effects of blast. Injury. 9, 313

United Stated National Bomb Date CeNTER (1974). General Information Bulletin 74-9

WATERworth, T A and CARR, M J T (1973). An analysis of the PM findings in the 21 victims of the Birmingham pub bombings. Injury. 7, 89

WILLIAMS, E R P (1941). Blast effects in warfare. British Journal of Surgery. 30, 38

ZUCKERMAN, S (1940). Experimental study of blast injuries to the lungs. Lancet ii, 219

ZuCKerman, S (1941). Discussion on the problems of blast injuries. Proceedings of the Royal Society of Medicine 34, 171

Preliminary Announcements-Corps Occasions for 1979

Provisional dates are as follows:-

RAMC Annual General Meetings of General and Officers Funds, 7 April

RAMC Association and Corps Mess Fund

Army Medical Services Swimming Gala

8 June

RAMC Officers' Dinner (7.15 for $8 \mathrm{pm}$ )

14 June

RAMC Officers' 'At Home' (4-6 pm)

6 July

Army Medical Services Sports Meeting

7 July

Army Medical Services' Drumhead Service at the RAMC Training

8 July

Centre and RAMC, RADC \& QARANC Associations Annual Lunch

RAMC Golfing Society-Spring Meeting-Worplesden Golf Club

14 May

Summer Meeting-North Hants Golf Club

4 July

Autumn Meeting-West Hill Golf Club

9 October

RAMC Retired Officers' Party

19 October

(For further details see the Army Medical Services Magazine, Winter Number) 